\title{
Design and Analysis of Three Phase Soft Switching Inverter Incorporating Fuzzy Logic Controller
}

\author{
Ismayil Kani .N, Manikandan. B. V, Premkumar. K
}

\begin{abstract}
A soft switching three phase inverter with the fuzzy logic system is proposed. The controller design is explained in this paper. The soft switching is achieved through zero voltage switching methods.The soft switching is attain through auxiliary circuits.Therefore, the auxiliary circuit will be enhanced the conversion efficiency, and the conduction loss will be scaled down. The performance of proposed controller is illustrated using MATLAB Simulink.The mode of the prototype is fabricated and tested. The Simulation and hardware results validate each other, which show that the presented method is both satisfactory and consistent with expectation.
\end{abstract}

Keywords : Zero voltage switching, soft switching, Fuzzy logic controller, switching losses, Three phase inverter.

\section{INTRODUCTION}

The inverter is mainly used many industrial applications, ups and drives. Mostly three phase inverter circuit filter size reduced due to inverter operated at high switching frequency. The switching frequency is directly proportional to voltage stress and switching losses .In this proposed method used zero voltage switching.

The high frequency operating inverter is mainly used many industrial applications . Because for higher frequency operation harmonics are eliminated and reduced filter size.so circuit design is simple.But high frequency operation, high switching losses, switching pressures, decreased performance, electromagnetic interference (EMI) and acoustic noise [1]. When the inverter switch is turn ON under zero voltage time achieved soft switching [2].

In [3] three phase circuit zero voltage switching inverter was presented. The supplementary circuit consist of one switch and two inductors are used. The main inverter in this topology consists of six switching devices which are operated

Revised Manuscript Received on December 30, 2019.

* Correspondence Author

*Ismayil kani.N, Asst. Prof., Department of EEE, S.Veerasamy Chettiar College of Engg \& Tech, Tamilnadu, India. Email id: ismayilkani@gmail.com

Manikandan. B. V, Senior Prof, Department of EEE, Mepco Schlenk Engineering, College, Tamil Nadu, India.

Email id: bvmani@mepcoeng.ac.in

Premkumar. K, Asso. Prof., Department of EEE, Rajalakshmi Engineering College, Tamilnadu, India.

Email id: prem.kamaraj@gmail.com

(C) The Authors. Published by Blue Eyes Intelligence Engineering and Sciences Publication (BEIESP). This is an open access article under the CC BY-NC-ND license (http://creativecommons.org/licenses/by-nc-nd/4.0/) by sinusoidal modulation techniques. In [4] the main switches of inverter turn off with ZCT and the auxiliary switches turn on with ZCS.The presented a new topology. It uses two auxiliary switches and a diode to provide the ZVS transitions for main switches. The PWM inverter is operated by the space vector modulation (SVM) technique. MOSFET switch is used.

In [5] implements for a control technique for resonant switch based DC-DC converters. The switch has some finite resistance provided during the ON period. The resistance changes the state. The resistance will be variable. In this converter . In [6] converters minimize the switching losses through the zero voltage switching methods.In this method no more additional components are used. The PWM pulse is controlled by shifting the duty cycle.

In [7] PWM converter achieved zero current transition with the help of a simple auxiliary circuit. This auxiliary circuit consists of a switch and capacitor. In this technique may also remove the rectifier switch's reverse recovery losses.

In [8] zero voltage switching method is proposed in the buck converter. This converter completely analysis switch current. A small margin gap is created between the drain current and load current. The proposed converter that consists of high frequency transformer and half bridge circuits.

In [9] Fuzzy logic controller based DC to DC converter was proposed.This converter working under hard switching technique. The converter output is managed by the fuzzy logic controller.This controller is designed simple rules.This controller providing better efficiency for all operating ranges.In [10] the fuzzy based converter was implemented . Evaluate the designed controller efficiency, they investigated the responses of a fuzzy controller for different parameters. The converter was proposed with the controller. The fuzzy logic and PI combination is used to achieve better efficiency comparability than other controllers. The simple rules are used so implementing part of the controller is very easy. The controlled efficiency is improved based on the system knowledge. The controller first stage receives the input from the small signal model of the converter.

\section{SYSTEM REPRESENTATION}

The proposed inverter block diagram is as shown in fig.1.The proposed inverter consist of DC supply, auxiliary circuits, DC link capacitor,Three phase inverter and controller. 
Mode $1(\mathbf{0} \leq \mathbf{t} \leq \mathbf{t} 1)$ : During this period the inverter switch S1 and S2 turn ON condition.

$$
I_{L r}(t)=\frac{V_{s}}{L_{r}}\left(t_{1}-t_{0}\right)
$$

Mode $2(\mathrm{t} 0 \leq \mathrm{t} \leq \mathrm{t} 1)$ : In this period the inverter switch $\mathrm{S} 1$ and S6 also turn ON under soft switching condition. In this mode end of this period switches S1 and S6 are turning OFF condition. The inductor

current increase linearly.

$$
V_{C_{S}}(t)=Z_{r}\left(I_{i}-I_{o}\right) \sin \omega_{r}\left(t_{2}-t_{1}\right)+V_{s}(1-
$$
$\left.\cos \omega_{r}\left(t_{2}-t_{1}\right)\right)$

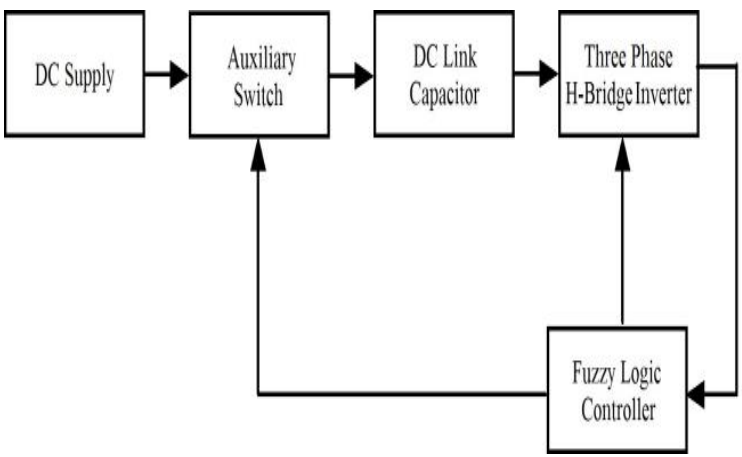

Fig. 1. Block diagram of the proposed inverter

Mode $3(\mathbf{t} 1 \leq \mathbf{t} \leq \mathbf{t} 2)$ : Switch Sdc is ON during this time. The resonant capacitor already charged. At $\mathrm{t} 1$, instant resonant capacitor charge is discharged through the DC link capacitor Cs. Starting the DC link connects Capacitor voltage zero.

$$
I_{L_{r}}\left(t_{2}\right)=\sqrt{\left(\frac{V_{s}}{z_{r}}\right)^{2}+\left(I_{i}-I_{o}\right)^{2}}+I_{o}
$$

Mode 4 (t2 $\leq \mathbf{t} \leq \mathbf{t} 3)$ : The DC linking capacitor Cs Charged during this time. The current of the inductor gradually reaches zero.

Mode 5 (t $3 \leq \mathbf{t} \leq \mathbf{t 4})$ : Switches S2, S3 switched ON in this mode under zero voltage condition. Then the DC link capacitor begins to discharge through the resonant capacitor and resonant inductor. This mode goes on until the voltage of Cs attain zero.

$$
V_{C_{r}}(t)=V_{s}-Z_{r} I_{i} \sin \left(\frac{\omega_{r}}{n} \frac{1}{\omega_{r}} \tan ^{-1}\left(\frac{V_{S}}{Z_{r}\left(I_{i}-I_{o}\right)}\right)\right)
$$

Mode 6 (t5 $\leq \mathbf{t} \leq \mathbf{t 6}$ ): .The resonant inductor current linearly increases. In this period the inverter switch S4 and S5 also turn ON condition.

The proposed inverter circuit diagram is as shown in fig 3.

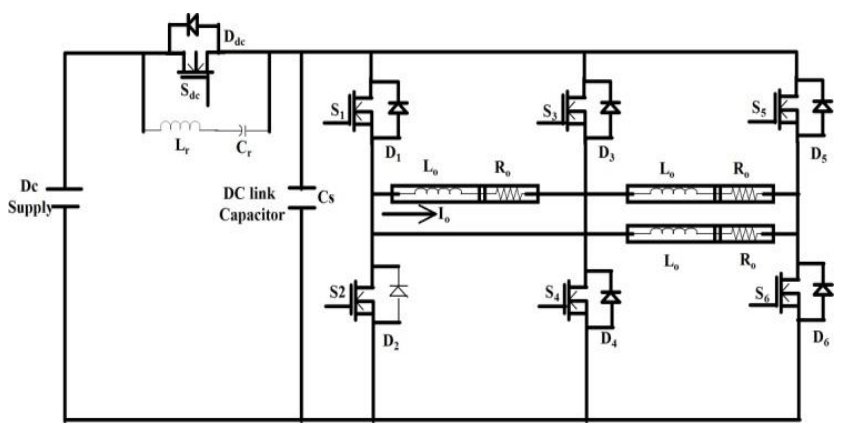

Fig. 2.Proposed inverter circuit diagram

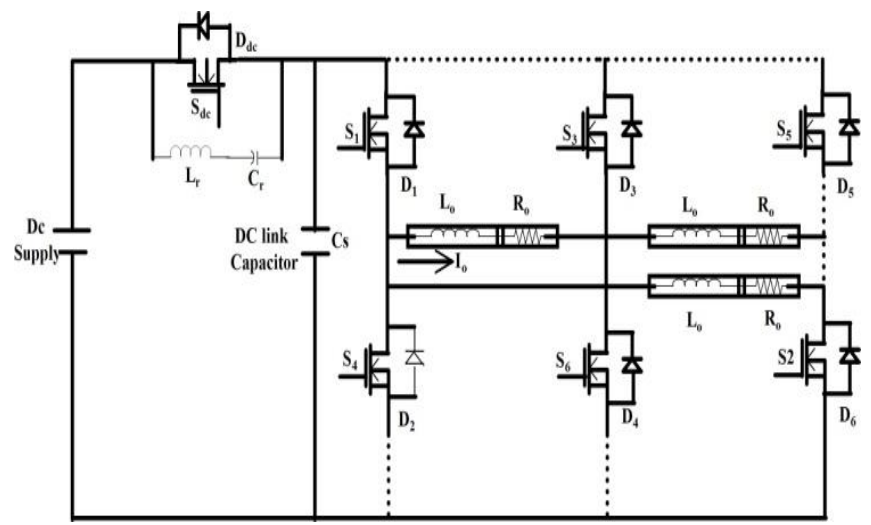

Interval 1

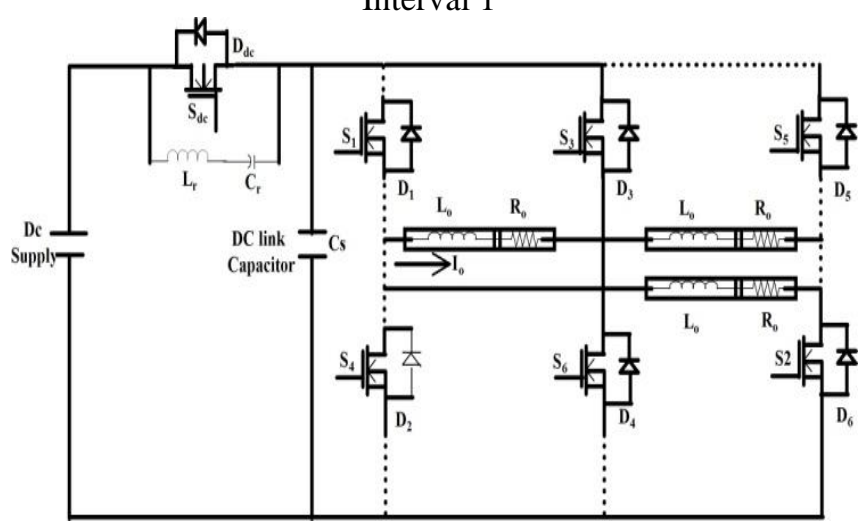

Interval 2

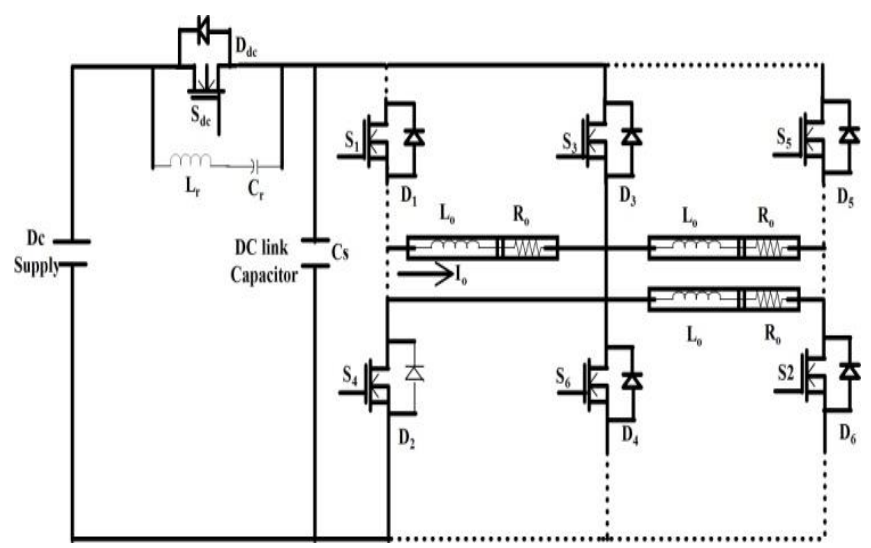

Interval 3

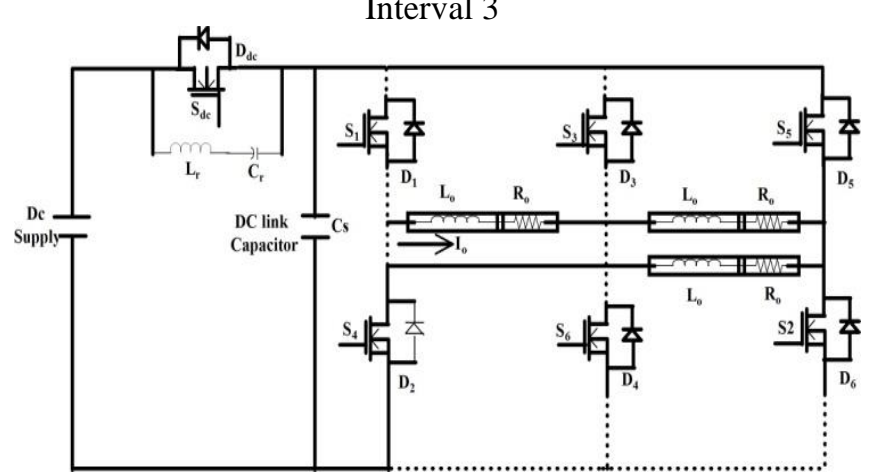

Interval 4 

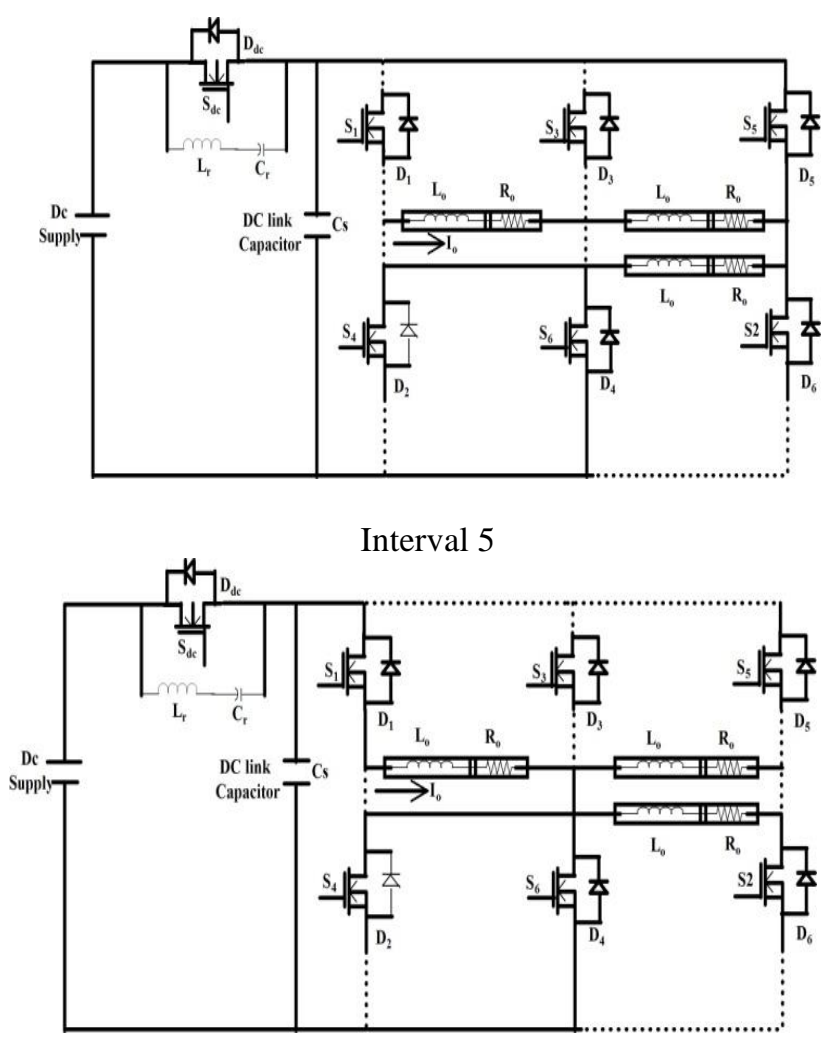

Interval 6

Fig. 3.Operation diagram of three phase inverter

The wave forms the three phase inverter main switch is $\mathrm{S} 1$ to $\mathrm{S} 6$ is considered equivalent to Sinv.

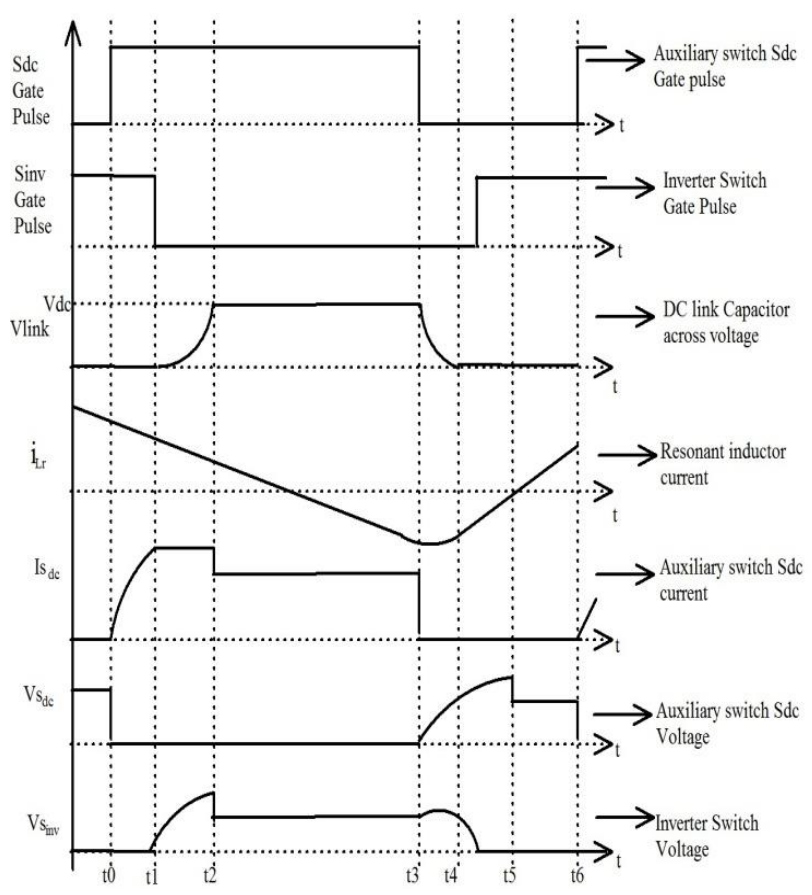

Fig. 4. Working waveform of proposed inverter

The advent of soft-switching techniques results in complex mathematical models and nonlinear control characteristics of the inverter. Hence, the design of linear control for quasi-resonant inverters becomes difficult. The mathematical model is not needed in the controller. Because of operating with imprecise inputs, manage nonlinearities, and has greater insensitivity to disruption compared to other nonlinear controllers. It usually performs other controllers with good practical knowledge in complex, nonlinear, or unknown systems. Hence, Conventional Fuzzy Logic Controllers (CFLCs) have proved to be viable controller.

Fuzzy logic controller is the one the non linear controller. The overall system speed is also improved as seen while the inverter is attached to the source by reducing the settling time. The controller disturbance may reject due to steady state value increase to zero.

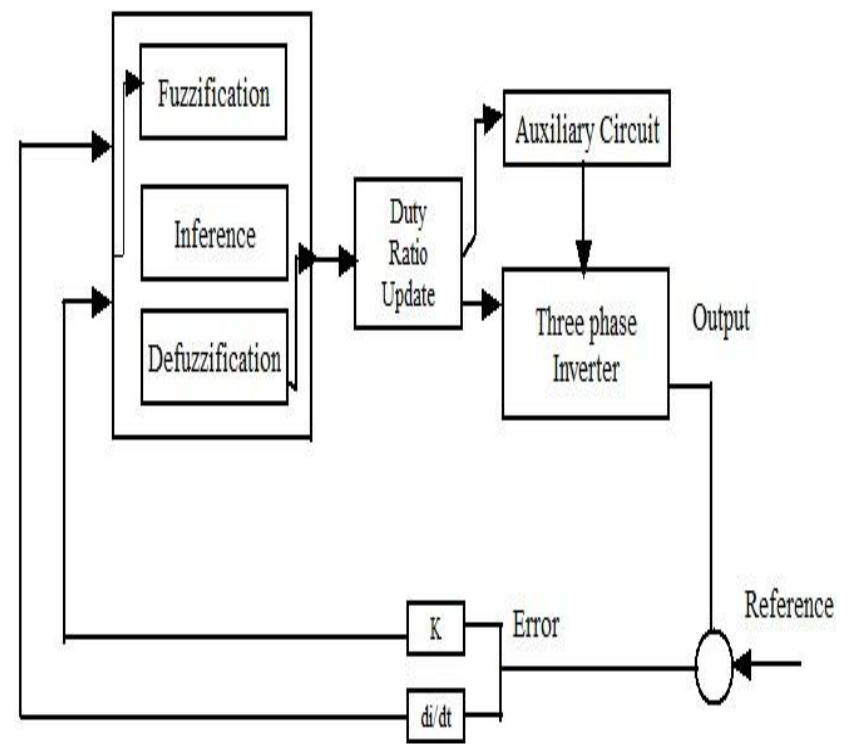

Fig. 5.Fuzzy system

The fuzzy logic controller algorithm is divided into three divisions.The first division is fuzzification, second one is Decision making and third division is defuzzification.The fuzzification is identified and translated into correct linguistic values. The duty cycle controlled by the controller.

The switching period, the duty ratio is updated and adjustment of the gain factor improves the controller's performance.

Input scaling makes available a way of connecting within a certain range the input of the fuzzy controller. Because the inference method is designed to function within the $[-1,1]$ limits.

\section{DESIGN CONSIDERATIONS}

In this section component design method is explained in detail.

\section{A. Resonant Capacitor (Cr)}

The voltage of the resonant capacitor is zero in the operation.This auxiliary circuit runs during this period. The large value of capacitor to remove the ripples. During this period capacitor current is same as that of inductor current.

\section{B. Resonant Inductor (Lr)}

The resonant inductors decide the Zero voltage Transition interval time. The choice of resonant inductors is an important part of the proposed inverter.

Published By:

Blue Eyes Intelligence Engineering

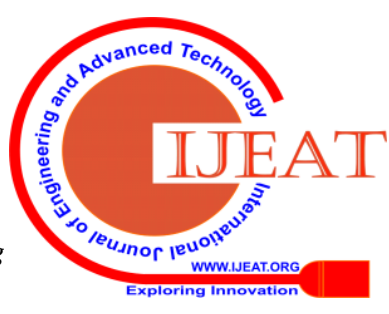


Design and Analysis of Three Phase Soft Switching Inverter Incorporating Fuzzy Logic Controller

\section{Resonant Frequency(fr)}

$$
f r=1 / \sqrt{(2 \pi L r C r)}
$$

D. Modulation Index

$$
M_{\max }=1-\left(T_{z v s}-T_{s}\right)
$$

\section{E. Snubber Capacitor (Cs)}

\section{$\mathrm{Cs}=$ Auxiliary circuit capacitance $+2 \mathrm{Csw}$}

$\mathrm{Csw}=\mathrm{C} 1=\mathrm{C} 2=\mathrm{C} 3=\mathrm{C} 4=\mathrm{C} 5=\mathrm{C} 6$

\section{SIMULATION CIRCUIT MODEL}

The Fuzzy Logic Controller Based soft switching Three Phased Inverter simulation diagram is as shown in Figure.6

The fuzzy levels are directly proportional to the input data resolution.So increase the fuzzy level automatically increased the input data resolution. The inputs are not quantized by assigning each input to absolutely one stage.The input is assigned to help with the membership grade fuzzy set.The bell shaped fuzzy set values is used in this proposed controller [10-32].

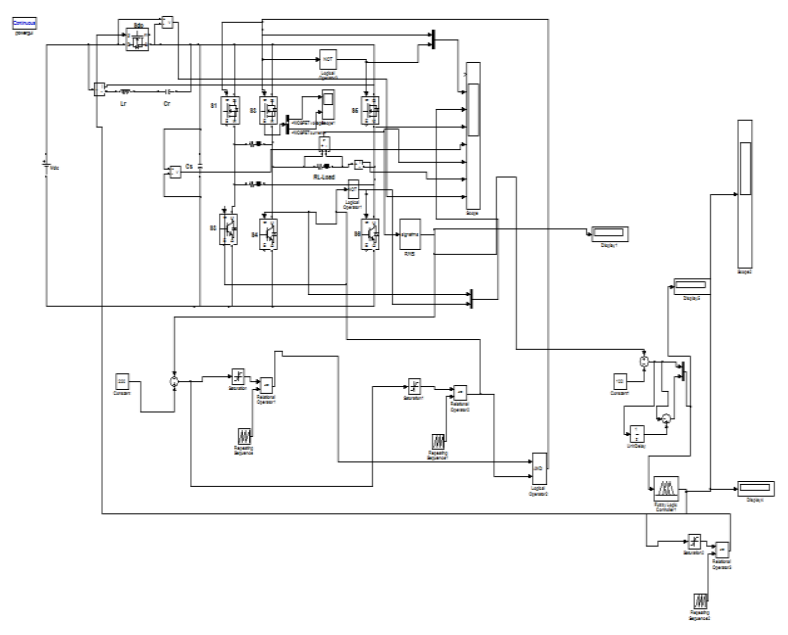

Fig. 6.Simulation diagram of the fuzzy logic controller based soft switching three phased inverter

The input and output signals are mapped through rule base.The fuzzy system and membership function are as shown in figure.

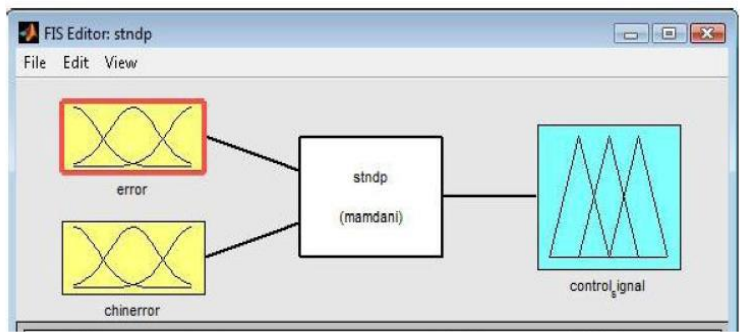

Fig. 7.Fuzzy logic controller

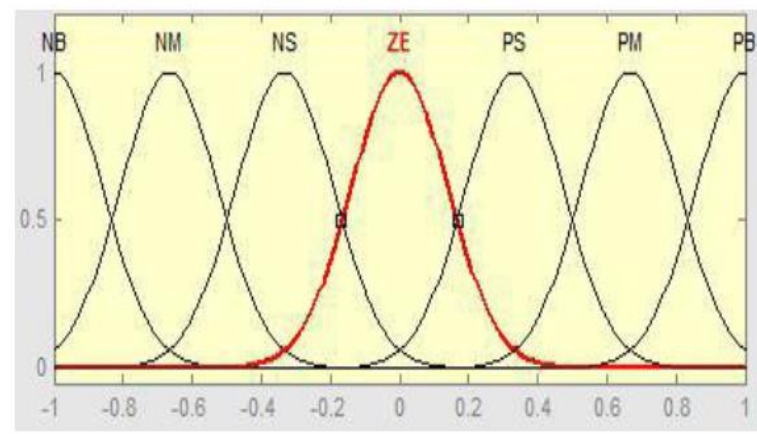

Fig. 8.Fuzzy system for the error input

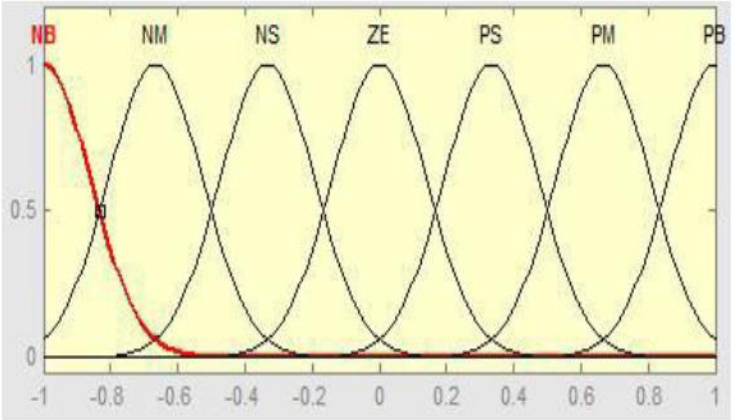

Fig. 9.Fuzzy system for the change in error input

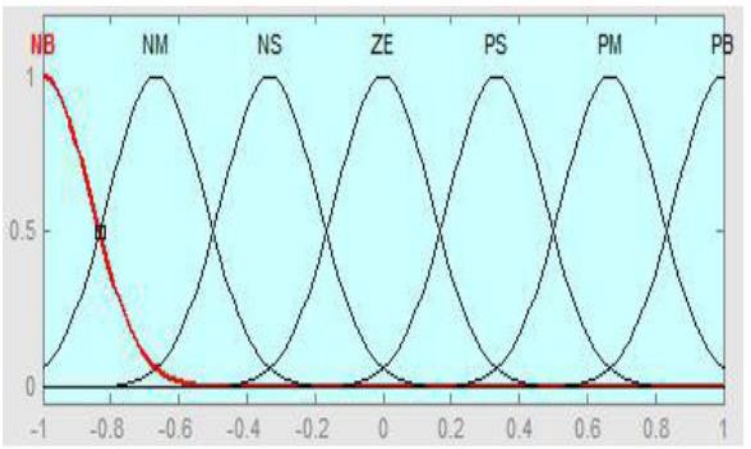

Fig. 10. Fuzzy system for the output

Table 1. Rule for the fuzzy system

\begin{tabular}{|c|c|c|c|c|c|}
\hline e & PB & PS & Z & NS & NB \\
\hline NB & Z & PS & PS & PB & PB \\
\hline NS & NS & Z & PS & PS & PB \\
\hline$Z$ & NS & NS & Z & PS & PS \\
\hline PS & NB & NS & NS & Z & PS \\
\hline PB & NB & NB & NS & NS & Z \\
\hline
\end{tabular}

\section{V.HARDWARE DESCRIPTION}

The proposed hardware is as shown in Figure 11. These proposed inverters was designed. 
The simulation and hardware result are analysis and verified. Duty cycle is controlled by fuzzy controller. The PIC 16F877A microcontroller's task is to measure the error and adjust the error, store these values, calculate the fuzzy controller output, evaluate the switching system duty cycle and perform electronic switching. The power losses are reduced due to Zero voltage switching conditions. In the proposed inverter switching frequency is $50 \mathrm{KHz}$, input voltage is $525 \mathrm{~V}$, the output line voltage $400 \mathrm{~V}$, phase voltage $260 \mathrm{~V}$ and output current is $20 \mathrm{~A}$.

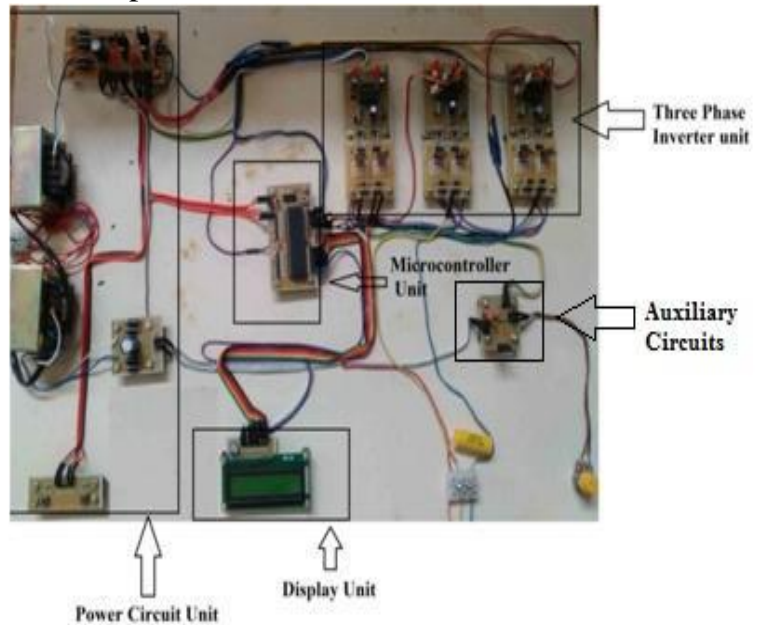

Fig. 11. Hardware setup of proposed fuzzy logic based soft switching inverter circuit

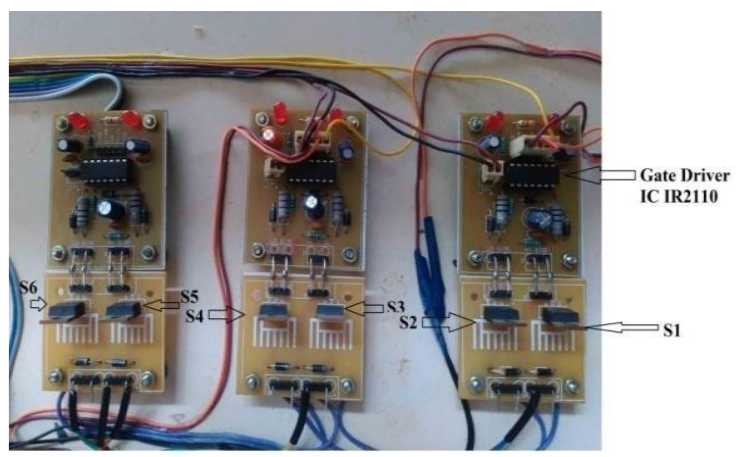

Fig. 12. Hardware setup prototype inverter circuit

Table 2. Simulation and hardware parameter

\begin{tabular}{|c|l|c|c|}
\hline \multirow{2}{*}{ S.No } & \multirow{2}{*}{ Parameter } & \multicolumn{2}{|c|}{ Value } \\
\cline { 3 - 4 } & & Simulation & Hardware \\
\hline 1. & Input voltage & $525 \mathrm{~V}$ & $525 \mathrm{~V}$ \\
\hline 2. & $\begin{array}{l}\text { Output voltage } \\
\text { (Line voltage) }\end{array}$ & $440 \mathrm{~V}$ & $440 \mathrm{~V}$ \\
\hline 3. & Phase voltage & $20 \mathrm{~V}$ & $20 \mathrm{~V}$ \\
\hline 4. & Output current & $20 \mathrm{~A}$ & $20 \mathrm{~A}$ \\
\hline 5. & Switching frequency & $50 \mathrm{KHz}$ & $50 \mathrm{KHz}$ \\
\hline 6. & Resonant inductor & $32 \mu \mathrm{H}$ & $32 \mu \mathrm{H}$ \\
\hline 7. & Resonant capacitor & $5 \mu \mathrm{F}$ & $5 \mu \mathrm{F}$ \\
\hline
\end{tabular}

\section{SIMULATION AND EXPERIMENTAL RESULT ANALYSIS}

The design parameters, i.e., input voltage, Output Voltage,Output current, Switching frequency, Resonant inductor and Resonant capacitor values for the three phase soft switched inverter with fuzzy logic control in simulation and Hardware is shown in Table.2.

In this proposed inverter, power electronics switches are operated at $50 \mathrm{kHz}$ frequency. The input voltage is set at 400 $\mathrm{V}$ DC inverter operated at high switching frequency.The input voltage $525 \mathrm{~V}$ DC supply is given to the inverter input side. The resonant inductor and resonant capacitor values are taken from design values .In this circuit used a resonant inductor and resonant capacitor values are $32 \mu \mathrm{H}$ and $5 \mu \mathrm{F}$. The output voltage of the system is $440 \mathrm{~V}$ line to line voltage.

The simulation result of output voltage of the proposed three phase soft switched inverter is shown in figure 13.

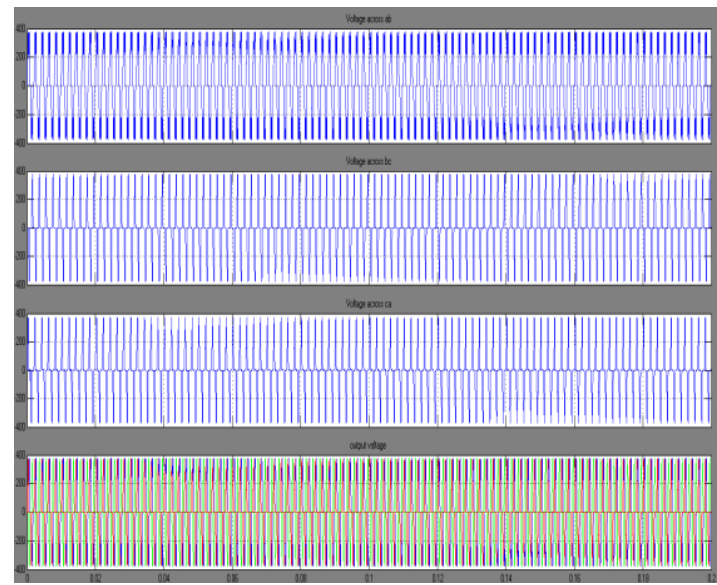

Fig. 13. Simulation Output voltage ,Phase voltage,Output cureent

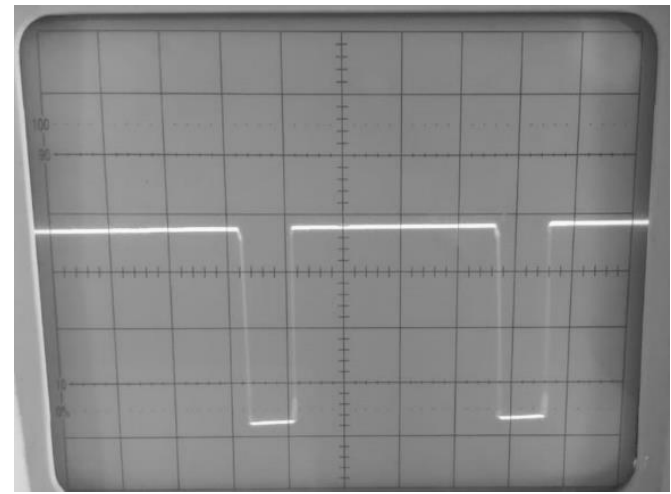

Fig. 14. Hardware Auxiliary switch Sdc gate pulse

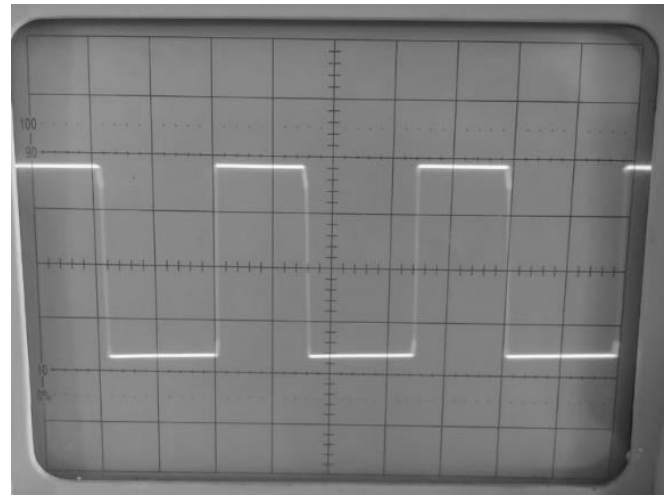

Fig. 15. Hardware Three phase inverter gate pulse

Published By:

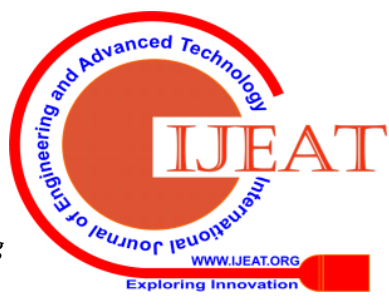




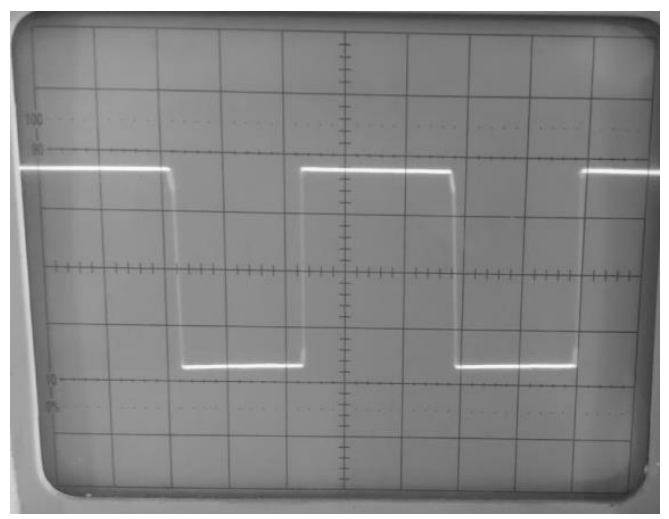

Fig. 16. Hardware Three phase inverter gate pulse

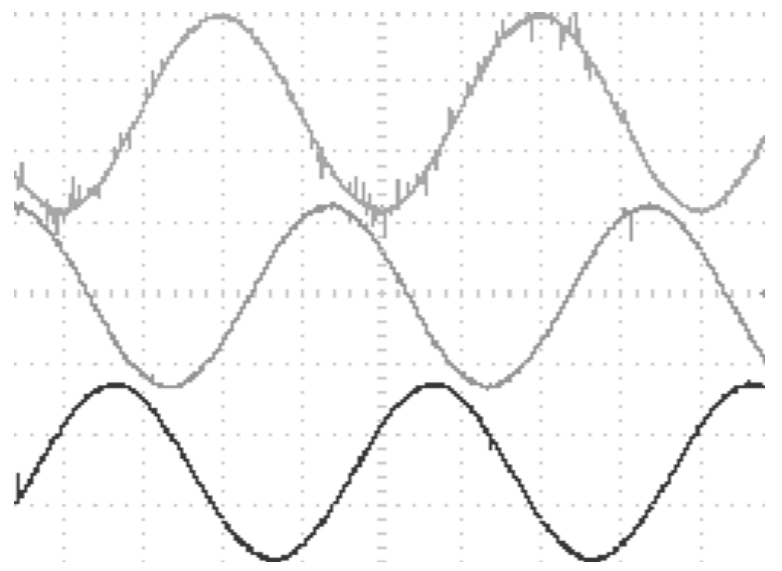

Fig. 17. Proposed inverter Hardware output voltage

Table 3. Simulation and hardware results

\begin{tabular}{|c|l|c|c|}
\hline S.No & \multirow{2}{*}{ Loading condition } & \multicolumn{2}{|c|}{ Switching Losses (W) } \\
\cline { 3 - 4 } & & Simulation & Hardware \\
\hline 1. & $\mathbf{2 5} \%$ of rated Power & 6.3 & 7.1 \\
\hline 2. & $\mathbf{5 0} \%$ of rated Power & 11.5 & 12.5 \\
\hline 3. & $\mathbf{7 5} \%$ of rated Power & 16.2 & 17.1 \\
\hline 4. & $\begin{array}{l}\mathbf{1 0 0} \% \text { of rated } \\
\text { Power }\end{array}$ & 20.2 & 22.3 \\
\hline
\end{tabular}

The gating pulses for power semiconductor,switches are shown in figure 14 to figure 16. The experimental output voltage of the proposed inverter is shown in figure 16. The system is tested with different loading conditions and switching losses are measured and it is tabulated in Table 3. From the result analysis, the switching losses are less for all operating conditions. The developed fuzzy logic controller is working accurately to reduce the switching losses in the inverter.

\section{CONCLUSION}

The proposed soft switching inverter was designed and implemented .The Proposed method is easily achieved soft switching. Additionally, Therefore, reduced the switch voltage stress through Zero voltage switching technique. Furthermore, the proposed inverter has no extra switches and transformers. So the cost of the inverter is also less. The performance of the proposed inverter simulation and hardware output was verified.

\section{REFERENCES}

1. Hong Mao, Osama Abdel Rahman \& Issa Batarseh 2008, "Zero voltage switching DC-DC converters with synchronous rectifiers"e, IEEE Trans. on Power Electronics, vol. 23, no. 1, pp. 369-378.

2. Li, Y, Lee, FC \& Boroyevich, D 2001, "A three-phase soft-transition inverter with a novel control strategy for zero-current and near zero voltage switching", IEEE Transactions on Power Electronics, vol. 16, no. 5 , pp. $710-722$

3. Mohammad Reza Amini \& Hosein Farzanehfard 2011, "Three-phase soft-switching inverter with minimum components", IEEE Transactions on Industrial Electronics, vol. 58, no. 6, pp. 2258-2264.

4. Xiao, HF, Lan, K, Zhou, B, Zhang, L \& Wu, ZZ 2015, "A family of zero-current-transition transformer less photovoltaic grid-connected inverter", IEEE Trans. on Power Electron., vol. 30, no. 6, pp. 3156-3165.

5. Trevor A Smith, Sima Dimitrijev \& Barry Harrison, H 2000, "Controlling a DC-DC converter by using the power MOSFET as a voltage controlled resistor", IEEE Trans. on Circuits and Systems-I:Fundamental Theory and Appli., vol. 47, no. 3, pp. 357-362.

6. Hong Mao, Osama Abdel Rahman \& Issa Batarseh 2008, "Zero voltage switching DC-DC converters with synchronous rectifiers", IEEE Trans. on Power Electronics, vol. 23, no. 1, pp. 369-378.

7. Ehsan Adib \& Hosein Farzanehfard 2009, "Family of isolated zero current transition PWM converters", Journal of Power Electronics, vol. 9, no. 2, pp. 156-163.

8. Yahaya, NZ, Begam, KM \& Awan, M 2011, "Experimental analysis of a new zero voltage switching synchronous rectifier buck converter", IET Power Electronics, vol. 4, no. 7, pp. 793-798.

9. Abdul R Ofoli \& Ahmed Rubaai 2006, "Real time implementation of a fuzzy logic controller for switch mode power stage DC-DC converters", IEEE Trans. on Industrial Applications, vol. 42, no. 6, pp. 1367-1374.

10. Feshki Farahani, H 2011, "Designing and implementation of a fuzzy controller for DC-DC converters and comparing with PI digital controller", Australian Journal of Basic and Applied Sciences, vol. 5 , no. 7, pp. 276-285.

11. Premkumar.K et al 2019, Fuzzy Anti-Windup PID Controlled Induction Motor, International Journal of Engineering and Advanced Technology, 9, 1, pages.184- 189.

12. T.Thamizhselvan et al. 2017, Maximum power point tracking algorithm for photovoltaic system using supervised online coactive neuro fuzzy inference system, Journal of Electrical Engineering, 17, 1, pages.270-286.

13. Premkumar.K et al. 2018, Stability and Performance Analysis of ANFIS Tuned PID Based Speed Controller for Brushless DC Motor, Current Signal Transduction Therapy, 13, 1, pages.19-30.

14. Premkumar, Kamaraj et al. (2018), Antlion Algorithm Optimized Fuzzy PID Supervised On-line Recurrent Fuzzy Neural Network Based Controller for Brushless DC Motor, Electric Power Components and Systems, 45, 20, pages.2304-2317.

15. Premkumar.K et al. 2015, GA-PSO optimized online ANFIS based speed controller for Brushless DC motor, Journal of Intelligent \& Fuzzy Systems, 28, 6, pages.2839-2850.

16. Premkumar.K et al. 2015, Online Fuzzy Supervised Learning of Radial Basis Function Neural Network Based Speed Controller for Brushless DC Motor, Lecture Notes in Electrical Engineering, 326 pages.1397-1405.

17. Premkumar.K et al. 2018, Novel bacterial foraging-based ANFIS for speed control of matrix converter-fed industrial BLDC motors operated under low speed and high torque, Neural Computing and Applications, 29, 12, pages.1411-1434.

18. John Prabu.M et al. 2016, Fuzzy supervised online coactive neuro-fuzzy inference system-based rotor position control of brushless DC motor, IET Power Electronics, 9, 11, pages.2229 - 2239.

19. Premkumar.K et al.2013, Adaptive fuzzy logic speed controller for brushless DC motor, 2013 International Conference on Power, Energy and Control (ICPEC), pages. 290-295.

20. Premkumar.K et al. 2015, Speed control of Brushless DC motor using bat algorithm optimized Adaptive Neuro-Fuzzy Inference System, Applied Soft Computing, 32, pages.403-419.

21. Premkumar.K et al. 2015, Fuzzy PID supervised online ANFIS based speed controller for brushless dc motor, Neurocomputing, 157, pages.76-90. 
22. Premkumar.K et al. 2016, Bat algorithm optimized fuzzy PD based speed controller for brushless direct current motor, Engineering Science and Technology, an International Journal, 19, 2, pages.818-840.

23. Premkumar.K et al. 2014, Adaptive Neuro-Fuzzy Inference System based speed controller for brushless DC motor, Neurocomputing, 138, pages.260-270.

24. D.Shyam et al. 2019, Symmetrically modified laddered H-bridge multilevel inverter with reduced configurational parameters, International Journal of Engineering and Advanced Technology, 9, 1, pages.5525-5532.

25. A.Alice Hepzibah and K.Premkumar (2019), ANFIS current-voltage controlled MPPT algorithm for solar powered brushless DC motor based water pump, Electrical Engineering. https://doi.org/10.1007/s00202-019-00885-8

26. A Ali Nazar et al. 2014, An ANFIS Based Advanced MPPT Control of a Wind-Solar Hybrid Power Generation System, international review of modelling and simulations, 7, 4, pages.638-643.

27. A.Nazar ali et al. 2015, A Single phase high efficient transformer less inverter for PV Grid connected power system using ISPWM technique, International Journal of Applied Engineering Research, 10, 9, pages.7489-7496.

28. A.Nazar Ali et al. 2014, Performance Enhancement of Hybrid Wind/Photo Voltaic System Using Z Source Inverter with Cuk-sepic Fused Converter, Research Journal of Applied Sciences, Engineering and Technology, 7, 19, pages.3964-3970.

29. K.Premkumar et al. 2019, Grey wolf Optimized PID Voltage and Power Factor Controlled AC to DC System, International Journal of Innovative Technology and Exploring Engineering, 9, 2, pages.5215-5220.

30. K.Sudha et al. 2019, Design and Simulation of Enhanced Adaptive Perturbation and Observe MPPT Algorithm for PV Fed DC to DC Boost Converter System, International Journal of Innovative Technology and Exploring Engineering, 9, 2, pages.1715-1719.

31. A.G. Karthikeyan et al. 2019, Multi Input and Multi Output Zeta Converter for Hybrid Renewable Energy Storage systems, International Journal of Innovative Technology and Exploring Engineering, 9, 2, pages. 4114-4119.

32. L. P. Sivakumar et al. 2019, Iot Sourced Real Time PV, Wind And Fuel Cell Models For Micro And Nano Grids, International Journal Of Scientific \& Technology Research, 8, 12, pages.988-993.

\section{AUTHORS PROFILE}

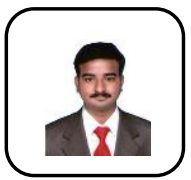

Ismayil kani. $\mathbf{N}$ is currently working as an Assitan professor in department of electrical \& electronics engineering at S.Veerasamy Chettiar College of Engineering and Technology, Puliyangudil, Tamilnadu, India. He is familiarize with following areas Power converters, electrical drives and softcomputing.

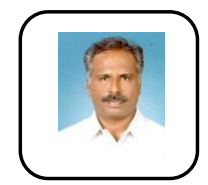

Manikandan.B.V is currently working as Senior Professor in department of electrical \& electronics engineering at Mepco Schlenk Engineering College, Tamilnadu, India. He is familiarize with following areas, power system, electrical machines, artificial intelligence, renewable energy.

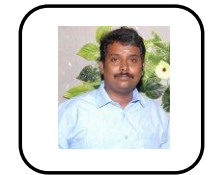

Premkumar.K is currently working as an Associate Professor in department of electrical \& electronics engineering at Rajalakshmi Engineering College, Tamil Nadu, India. He is familiarize with following areas, Design of PID controller, Design of Artificial intelligence controller, electrical drives, micro grid, IoT, renewable energy. 